\title{
On the Ordnance Survey
}

\section{Colonel James R.E., F.R.S., \&c.}

To cite this article: Colonel James R.E., F.R.S., \&c. (1859) On the Ordnance Survey, Royal United Services Institution. Journal, 3:9, 28-38, DOI: 10.1080/03071845909422968

To link to this article: http://dx.doi.org/10.1080/03071845909422968

\section{册 Published online: 25 Sep 2009.}

Submit your article to this journal

Џll Article views: 6

Q View related articles $\longleftarrow$ 
Friday, February 4th, 1859.

Lieut.-Gen. Sir. WILLIAM CODRINGTON, K.C.B., M.P., in the Chair.

\section{ON 'THE ORDNANCE SURVEY. \\ BY Coloxel Jases, R.F., F.R.S., \&c.}

I AM afraid you will find this a very dry subject, but I will endenvour to go rapidly over the various points, more with the view of giving a correct outline of the whole proceedings and history of the Survey, than of going into minute details, which would be more adapted for a book than a leoture.

The history of our Survey presents a most remarkable example of that gradual and slow developement of just views which we often witness on other questions in this country; and as there has been so much discussion, and so many changes in the orders which have been issued from time to time respecting it, I have gladly availed myself of this opportunity to explain to the Officers of the Army and Navy, and the public generally, the exact state of the question at the present moment.

The survey commeneed under General Roy, R.E. in 1785; but the object then in view was simply the production of a military map on a 1 -inch scale, and that survey, with considerable interruption, consequent upon the wars then going on, had extended in 1824 from the Land's End to the boundary of Yorkshire and Lancashire, including the whole of Wales. It was then decided that there should be a general valuation of Ireland, and that, as 'a necessary basis for that valuation, there should be a townland survey; Ireland being divided into smaller divisions of parishe: than England, ealled townlands, which are generally co-extensive with private properties, averaging about 300 acres each.

The whole survey force was then sent to Ireland, and the surrey of Great Britain was altogether suspended. Wre commenced first in the North of Ireland, I myself taking part in the survey. To obtain accurately the acrenge of the townlands, which was at first supposed would be all that would be required, it was decided that the scale should be six inches to the mile; and then commeneed that series of mistakes which has interfered witl our proceedings up to the present day. For no sooner had we completed the survey of four counties, according to our instructions, than it was found that the skeleton plan, containing the mere boundary of the townlands and the principal roads and rivers, was altogether insufficient; and that every field and garden must be surveyed to enable the tenement valuation to be made. We had consequently again to proceed to the North and complete the survey, and we have hardly completed it yet, having to put in every single field through the northern counties of Ireland. Our parties are now finishing it-they are in Armagh, and have nearly completed that county; and, when that is finished, I trust it will close the six-inch survey of Ireland. But the mistake and 


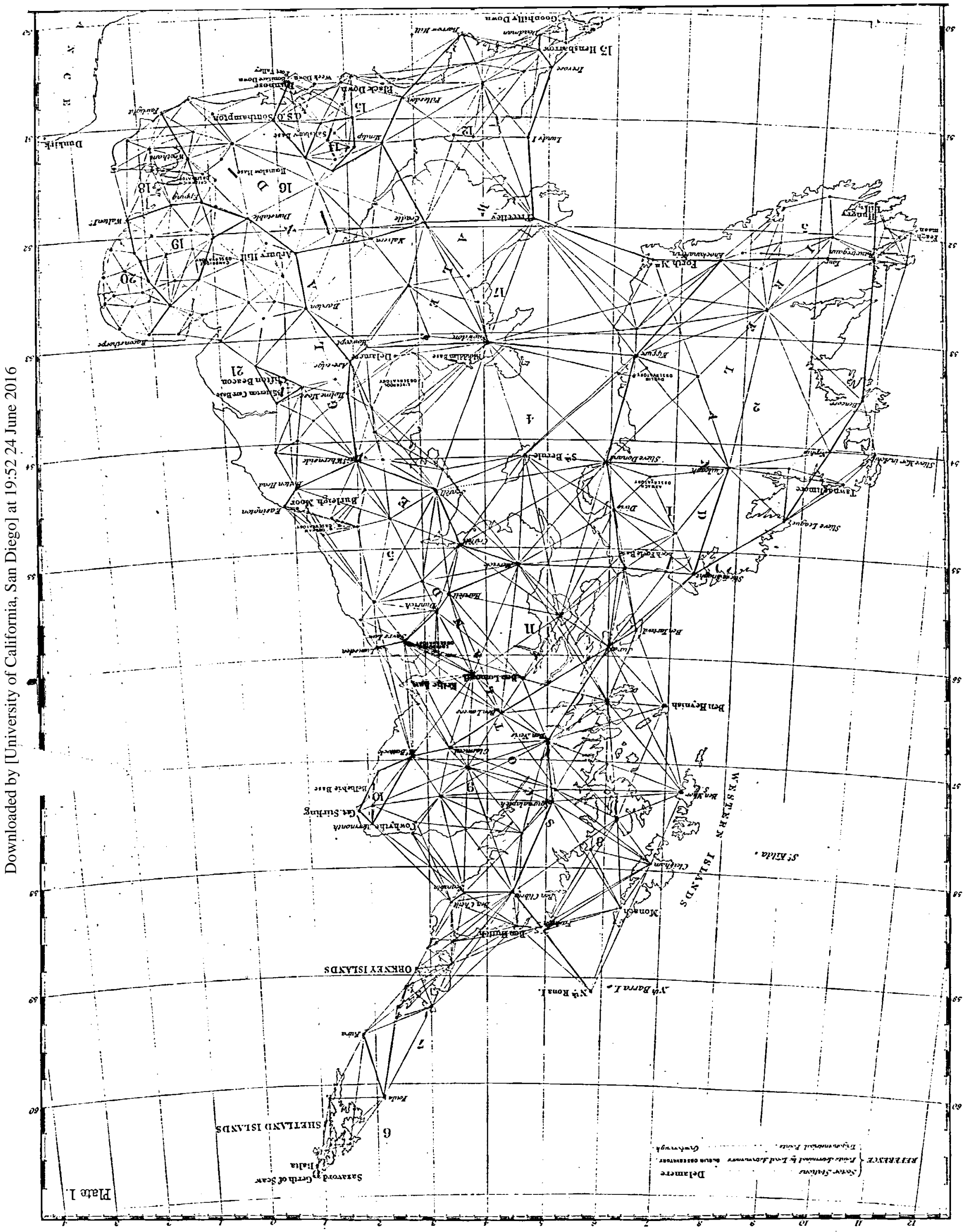


its consequences do not end there. Under the newly-constituted court, which was called the Encumbered Estates Court, and which is now called the Landed Estates Court; a vast amount of property is being constantly sold; and for the purpose of sale they require accurate plans of the property. When you bear in mind that on the six-inch scale sixteen acres occupy one square inch only, you will understand how inadequately represented upon that scale were the snall sub-divisions of property. By a curious coincidence, just as a royal commission on the survey had recommended the 25-inch scale for the surrey of Great Britain, the judges of the Landed Estates Court in Ireland made an application, which has received the sanction of the Treasury, for the introduction of the 25inch scale for Ireland, for the plans of all estates sold under the Landed Estates Court.

The survey of Ireland was completed on the six-inch seale; and, aithough it is to be regretted that it was not made in the first instance on a much larger scale, still it was found to be of such immense benefit as compare 1 with the one-inch, that, when we resumed the survey of Great Britain in the North of England and South of Scotland, we were ordered to procecd upon the six-inch scale, as we had done in Ireland; and we completed the whole of Yorkshire and Lancashire, and several small counties in the South of Scotland on that scale. After we had completed Yorkshire and Iancashiire, and several of the counties in Scotland, there commenced a discussion upon what was the proper scale for the plans, which, if it is quite closed, has only just been brought to a close; a Royal conmission, composed of many of the most distinguished men of the dny, of which Lord Wroltesley, President of the lloyal Society, was Chairman, having unanimously recommended the adoption of the 25-inch scale as the national scale for our cadastral survey.

With these preliminary observations, I may proceed to describe the operations of the survey itself. The first requisite for a survey is, of course, a triangulation. When i say a survey, I speak of the survey of a great kin: dom, not of a limited district. It is absolutely necessary that you shou." have an accurate triangulation. And, as a preliminary to obtaining an accurate triangulation, you must hare accurate bases measured.

Plate I. represents the trinngulation which we have carried over the whole of the United Kingdom, from the Scilly Islands to the Shetland Islands. The bases that have been measured, and from which all the distances in that triangulation have been computed, were those on Salisbury Plain, at Iough Foylc in Ireland, Misterton Car in Nottinghamshire, Rhuddlan MIarsh in the North of Wales, and Belhelvie in Aberdeenshire. The two first were measured with Colby's compensation bars, the others with steel chains 100 feet long. (Plate II. fig. 1.)

The compensation bars for the measurement of bases, which were designed by the late General Colby, are made in this way : a bar of brass, $\Lambda \mathrm{B}$, is firmly connected to an iron bar, $\mathrm{CD}$, at their centres; these are again connected at each end with tro iron tongues, $E \Lambda, F \mathrm{~B}$, moveable on pirots. On the projecting portions at E F a fine dot is made on a piece of platinum, and it is so arranged that the distance from the dot to the centre of the pirot at $\mathbf{c}$ shall be to the distance of the same dot to the 
centre of the pirot at $A$ in the ratio of the expansion or contraction of the iron bar $C D$, to the expansion or contraction of the brass bar $\wedge$. By this arrangement it will be seen that the distance betreen the dots at $E$ and $F$ remain at the uniform distance of $\mathbf{1 0}$ feet under every change of temperature.

These bars, in the nctual mensurement of the bases, are laid perfectly horizontal by means of levels, and ranged in a perfectly straight line by means of sights upon them, and a directing telescope.

To prevent any disturbance in the position of the first laid'bar, when the next to be placed in its position is brought up, a double microscope (like an opera glass, the distance between the foci of which is exactly 6 inches) is placed on the end of the bar about to be laid in position; by this arrangement the first laid bars are never touched or disturbed, and the exact distance of 6 inches between the foci of the microscopes is preserred by compensation bars on the same principle as in the 10-foot bars.

Mr. Babbage and Sir Joln Herenhel were present when upon Lough Foyle 500 fect of part of the base of scren miles were remeasured, and, testing it by the finest dot that was mado with the point of a fine needle, it was found to be only the third of a dot in error; such was the extreme accuracy with which the operation was carried on.

It is of littlo consequence to obtain extreme accuracy in one portion of a work unless wo obtain the samo accuracy in every other portion. The horizontal angles of the triangulation, as well as the rertical angles and azimuthal bearings of the stations, were measured with theodolites 3 feet in diameter. These magnificent theodolites were made by the great Ramsden, who made one for the Royal Society and one for the MnsterGeneral of the Ordnance. They wore the first instruments which .mensured the spherical excesș. All tho angles in the triangulation having bcen observed, we laad to mincounter a most formidable question, namely, the correction of the $c-$-2rved angles so as to render the tringulation perfectly consistent in itself; that is to say, so that the sum of the three angles in every triangle should be $180^{\circ}$, and the sum round every station $360^{\circ}$ : to do that required a mass of calculation perfectly astounding; and, bold as the Russian engineers are in undertaking such questions, they were astonished when told that we lind overcome the difficulty. The calculations which we had to make involved the solving of equations with thirty-sis unknown quantitics. For my part I havo always considered three to be enongh for a man with a moderate appetite for figures. The result of the triangulation has been this: By computing through the triangulation the length of one base from the other, and comparing the computed length with the measured distances, we found a difference of only 5 inches, the interval between Salisbury Plain and Lough Foyle being from 300 to $\mathbf{4 0 0}$ miles; and, when we compared the computed with the measured length of the base in $\Lambda$ berdeenshire, there was a difference of not more thnn 3 inches. Therefore we have a perfect moral certainty that we have a triangulation (which is the essential basis of accuraoy) determined with a perfection which was never before attrined.

We now come to another important point. It is also absolutely necessary that we should accurately determine the figure and dimensions of. 


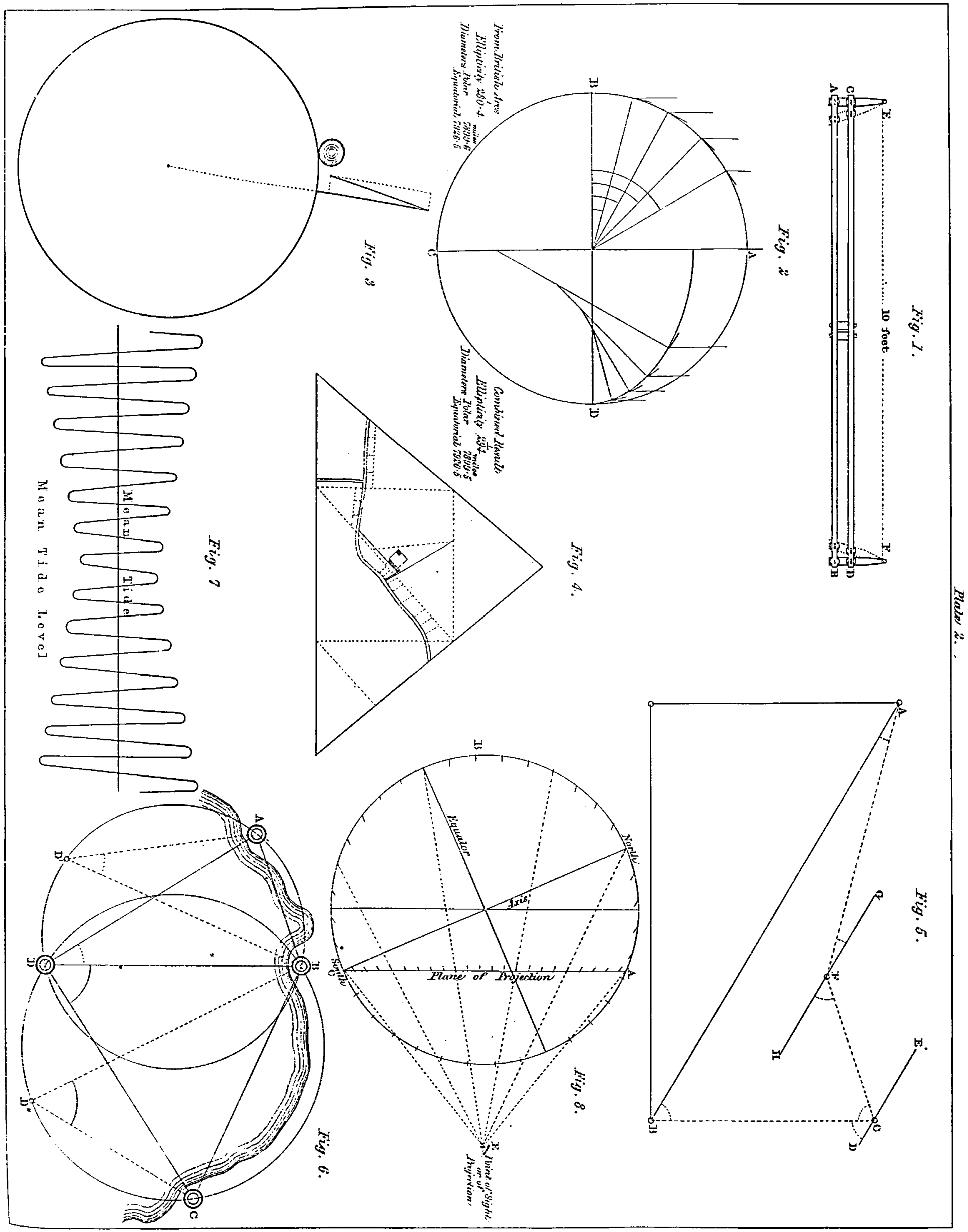


the carth. Suppose you have a globe that is scored over with meridians and parallels. If a triangulation like a netwrork is placed over it, you will understand that, if the globe is either too large or too small, the points of the angles will not rench their required latitudes and longitudes; and therefore it is absolutely necessary, in extensive surveys, that we should get a perfect knowledge of the figure and dimensions of the earth. From our own series of triangles we computed the 10 degrees between the Shetlands and the Isle of Wight. If we multiply that by 36, we get the circumference of the globe, supposing the carth to be a perfect sphere. If it were a perfect sphere, every degree of latitude along a meridian would bo of equal length. Bui we find, if we measure a degreo of latitude in the Sonth of England, and another near Edinburgh, and another in the Shetland Islands, the degree is 100 yards longer at Edinburgh than at Southampton, and 200 yards longer in the Shetlands; this is caused by the ellipticity of the carth or the flattening at the poles. (Plate II. fig. 2.)

On the diagram (fig. $\Lambda, \mathrm{n}, \mathrm{c}$ ) is the section of a perfect sphere, and the distances increase uniformly with the latitudes. But on the other side of the diagram, $A, D, C$, is the section of an clipsoid, and you will see that the distances for equal latitudes increase towards the poles; by the law of this increase we are able to determine the nature of the curve that is followed. The earth has an ellipticity of $\frac{1}{39 \pi}$, the polar diameter of the earth being $7899 \cdot 5$ miles, and the equatorial. diameter being 7926.5 . In this investigation we meet with a great difficulty, arising from the local attraction of the mountains which surround tho stations at which the observations are taken. If for instance we takc points north and south of Arthur's Scat, tho attraction of the mountain would draw in the plumb-line torards it. 'This is made sensible by the levels attached to the instrument, the observed difference of latitude between the two stations being greater than is duc to the distance along the meridian. IIaving climinated the errors arising from this eause, we can determine the true figure of the earth, and we also obtain the data for detcrmining the density of the earth, we can find the specifio gravity of the mountain, and we know that the foree of its attrnction is in proportion to the mass, and in the inverse ratio of the square of the distance. So ngain the attraction of the earth itself is in proportion to its mass, and in the inverse ratio of the square of the radius. The ratio of these two attractions gives us the tangent of the angle of deflection in the plumb-line. If you supposo the mass of Arthur's Seat to be in the form of a small globe (Plate II. fig. 3), whilst this large globe represents the carth, then the plumb line, insteal of going straight to the centre of the earth, will be drawn in the direction of the smaller globe. The resnlt of this investigation is, that the attraction of the mountain was found to be about one-linlf only of what it would hare been if it was of the same specific gravity as the earth, and that, the specific gravity of the mountain being $2 \cdot 75$, the specific gravitv or mean density of the earth is $5 \cdot 310$.

The larger trinngulation, the sides of which are abont 100 miles long, lnving been established, it was subdivided into smaller triangles of about 10 or 15 miles a side. 'The triangulation being completed, the "detailed survey " is commenced. In the organisation of the surrey, the work is. 
divided into several branches of which the triangulation which I have been describing forms the first; then follows the levelling, then the detailed survey, which $I$ am about to refer to, then the preparation of the manuscript plans, and their final publication.

The whole survey force is $1,500 \mathrm{men}$, in which four companies of the loyal Engineers are employed, forming a military nucleus which keeps all in order. 'This force is divided into sections for each branch of the work. In fact, we carry out the subdivision of labour to as full an extent as a manufacturer would in any other department of work; and we find great benefit to arise from this system. We find also that we can now advantageously, wad at a great reduction of cost, introduce the system of piece-work, and we have recourse to it wherever the nature of the work admits of its adoption.

I speak in the presence of many gentlemen in the Army and Navy who are familiar with the ordinary modes of surveying, and to whom it is unnecessary to describe many things I am about to refer to. But, as the sailors say, to keep the convoy together we must regulate our rate of going by the slowest ship. The system of survey which we prefer, when practicable, is to give a man a triangle, or half-a-dozen triangles; he chains along the sides of each triangle, leaving piquets upon the lines as he proceeds in such positions as he thinks most convenient for taking the detail of the survey. Our reason for this is, that, having computed the distances from our base line, we know, to the fraction of an inch, what the length of each side is, and when we see the field-book brought in, we can tell whether the chaining of the three sides is accurate, and when we lay down the work on the plan, it will be seen that the cross lines will not fit into their places, unless they are also of the exact dimensions that they should be. Thereforc, although we do not watch the proceedings of the surveyor, we have a most thorough check upon the quality as well as the quantity of his work. (Plate II. fig. 4.)

This mode of surveying, viz. by chaining all the sides of the triangles, and a great number of internal lines, all connected with the sides, is the method we employ for the survey of the cultivated districts. The method we employ in the uncultivated districts, and which we must employ in the highlands, where it would be impossible to chain the sides of the triangles in the way $I$ have described, is what is called traverse surveying.

In surveying by traverses along the course of streams or roads, the theodolite is employed, and is first put up at one of the trigonometrical stations, and one of the sides of the triangle is talien as a meridian to work from. (Plate II. fig. 5.)

The theodolite being placed in the direction of the meridian, $\mathrm{B} A$, the bearing of the first station, $c$, in the traverse is observed; then clamping the instrument, and chaining the line B $\mathrm{c}$, set up the instrument again it c, with the plates clamped, and after clamping the underplate, relense tne upper and take the next forward angle to $F$, and so on through the whole traverse. By following this course, the bearings are always taken in referenue to the direction of the line taken as the first meridian, because the first observed angle, $A$ i $c$, is equal to the angle $\mathrm{b} \mathrm{c}$, in which position the instrument has been placed at $c$, and the line $E \mathrm{D}$ is parallel to the line $A B_{2}$ from which we started. A similar system will be pursued 
at all the other stations, and when the traverse is closed at $\Lambda$, the angle B A $F$, if no mistake has been made, will be equal to the last observed angle A F G. The surveyor, therefore, has the means limself of knowing whether any error has been made in the angles during the course of the traverse.

Another mode of checking the rork, and which cnables us to say in what part of a traverse any error may have been made, is analogous to that adopted by sailors for fixing the position of any object near the coast. If he has three points, as A B c, (Plate II. fig. 6,) determined on land, by taking the two angles which $\mathrm{A}$ E, $\mathrm{D}$ C subtend from a bont at $\mathrm{D}$, he fixes his position, because there is only the point $D$ where the two circumscribing circles intersect each other, from which they could have becn observed. By taking the bearing of the trigonometrical station, the traverse surveyor fixes his position in like manuer, and provides checks for his work as it proceeds.

I will next refer to the levels. The datum lerel assumed for the survey is that of mean tide. (Plate $\Pi$. fig. 7.) The tides, from ligh spring tides, continue to descend from day to day, till they come down to neap tide, again rising to spring tides; thus oscillating daily above and below the level of mean tide, which is the datum which we take, and all our levels are referred to that point. TVe take tidal observations at a great number of places all round the coast; and level along from one to the other; we thus establish a series of levels, which again become points of reference for branch lines of levels in erery direction. These again become the initial points from which contours can be set off, and the data obtained for making a model. An ordinary survey gives the plane surface of the ground only, but a contoured plan gives the data for a mor $^{3} \mathrm{~s}$, for it gives us the relief also.

Having described our methods of surveying, we must refer to the series of maps which the Royal Commissioners have recommended the Government to adopt, and which, subject to the approval of Parliament, we are ordered to go on witls. For towns we have the large survey on the one five hundredth scale, 500 fect being represented by 1 foot, wr 42 feet by 1 inch.

For the parishes we have the 25-inch scale, which has been so much discussed. The 25 -inch scale, which is equal to 1 square inch to an acre, is limited to the cultivated districts.

For the uncultivated districts of the counties, the scale is 6 inches to the mile, the 25-inch plans of the cultivated districts being reduced to the 6-inch scale, so as to complete the counties on one uniform scale.

We again reduce the 6 -inch plans to the 1 -inch scale, to form the ordinary 1-inch map. Therefore, for certain portions of the country we have four scales. One great object in having this series of plans is to carry into effect that great measure which I believe to be most inportant for the agricultural and commercial interests of this country, namely, the facilitating the transfer of property. It is a question which, as I see by IIer Majesty's speech from the Throne, is now at the commencement of this session to be taken up by the Government.

I propose now to explain the manner in which we make the seductions of the plans by photography. Having that series of maps to make which

vol. 11 . 
I have described, it would be the most tedious and expensive thing imaginable, having the large plans upon the 25 -inch scale, again to replot the 25-inch to form the 6-inch, and again to replot the 6 -inch to the 1-inch, it being at the same time necessary that everything should be represented accurately. Seeing the enormous amount of labour involved by the whole process of reduction by the pentagraph, I directed my attention to the possibility of getting some other method; and, although I was at first discouraged by the photographers whom I consulted, I have now entirely succeeded by means of photography, and I may say with absolute accuracy ; for a commission, of which Sir Roderick Murchison was chairman, has investigated the subject, and it is stated in the report that the greatest error is the one four hundredth part of an inch; therefore, practically, we may consider the reduction as being absolutely correct. In making the reductions we use the ordinary collodion process. [Several of the negatives vere here exhibited, as well as a great number of positive impressions which icere produced from them.] In some instr. several sheets hare been joined together, and by the manner in which they join, it was evident that they were perfectly accurate, for if they were not so, the lines would not correspond. The success which we have achieved is, perbaps, more important as a question of time than of mr 1ey; for the question was, how it was to be done at all, so as to get out the maps in any reasonable time; . we now find that by the aid of photography we can strike off any number that may be required in a short time, and without the slightest difficulty. With regard to the saving of money, it saves us at the present moment, in wages merely, upwards of $£ 1,600$ a year; and if the survey should be continued on the large scale, it would sare $£ 32,000$, or not less than $£ 40,000$ in all.

The next thing was to introduce an expeditious mode of publishing the plans on a large scale. We first tried the system of lithography, but we eventually determined to try zincography. In the first place, the lithographic stones were enormously expensive; secondly, they were of tremendous weight, being sereral hundred weight to lift; and, what was still worse, when they had cost us $f 4$ or $£ 5$ they frequently broke. We therefore determined to try zincography. In that attempt we have succeeded beyond all expectntion; and I take no credit to myself for it, because I have been assisted by intelligent non-commissioned officers and others who carry oitt onc's idens in a manner most gratifying to me.as superintendent. [A small press was here exhibited to show how the operation uas performed.]

Colonel James then proceeded: I should have explained before, that Corporal Neil has placed in the press a thin piece of tracing paper, which is laid over a plan and traced; all the figures referring to the fields, the acreage of which is given, are put in by mechanical means; not only is that done upon the tracing, but it is also done upon that which may be called the manuscript map. We have electrotyped the stamps, and the result is, that when the plans come in from parties stationed in different places, as at Perth, Newcastle, and Carlisle, for instance, you cannot tell one from the other-Corporal Neil has one of those tracings. You will see in at short time that he will produce a plate: the impressions will 
not be quite perfect at first, but if jou want 500 they will improve as they go on.

After we hare reduced the plans by photography, it is necessary to engrave the 6-inch sheets upon copper. It is so arranged that 16 of the reductions exactly cover the area of one of the sheets of the 6-inch survey, and therefore the reductions can be brought into their exact positions by placing the tracings from them over the marginal lines and trigonometrical stations as drawn upon the copper plate. The engraved work is cut into the plate; but we have introduced a great number of mechanical contrivances, as for making the letters, stamps for the trees, and ruling machines for the tints, and so on, which economizes the labour of engraving; the result is, that we produce the plates from which the impressions are taken as you now see them, and at a very much diminished cost as compared to what it was formerly.

We now come to the sketching of the ground. We take the 6-inch impressions and put them into the hands of the field-parties to sketch the ground on. It was useless labour to make a reduced copy in manuscript when we had the engraved plan which we could give the men, and therefore we use the engraved impression. The ground having been sketched by the field-sketchers, as we term them, a drawing from the field sketch is next made on an outline impression on the 1-inch scale, and from that is engraved the 1 -inch map which the public receive. You will observe the necessity of having the intermediate hill drawing, which requires a very first-rate artist to draw: this is a step which we should be very glad indeed to get rid of, and I have had a great number of experiments made with a view of effecting that object, and to get a copy by photography of the original sketches, straight down upon the plates, without the intervention of that drawing. I have here four experimental sheets intended to be sent to India, and I think we have in that'trial sheet alone a pretty good proof that we shall succeed.

Any gentlemen who have examined the old sheets of the map of England must have observed how very much the plates have been worn in printing, and it has been a source to us of constant expense, and I may say of shame, to be continually repairing our plates and giving to the public rery damaged and bad impressions. We now get rid of the whole of that difficulty. As soon as an original plate-of Edinburgh for example-is engraved, we put it in the electrotype battery (Smee's battery). Upon that original engraved plate we throw down by the battery a plate which is called the "matrix," and which is therefore in relief, and then again we throw down another plate upon the matrix which is the exact duplicate of the original plate; and so, for the mere expenditure of zinc and acid, we are enabled to produce any number of exact duplicates of the original plate. It is impossible to exaggerate the advantage which this has been to us. In the first place Sir Roderick Murchison, for example, requires a special map for his geological survey, and we take a plate for geology, lcaving our original plate untouched. Again, Te require indexes to the counties, examples of which are on the wall, and we take another plate for them. The indexes to the survey are by counties, whilst the engraving of the D 2 
1-inch map is by rectangular shects. To make the indexes, 1 e simply cut out those portions of several matrixes which would form one county. These several parts are then put together, and the electrotype copy taken, we are thus cnabled to bring out the county map, which is a most beautiful engraving, and yet the hand of man has never touched it.

The accuracy with which these duplicates, made by the electrotype process, are made, and the manner in which the metal finds its way into every crevice of the engraving, is to me one of the most wonderful things I know of, and the more I contemplate it, the more astonished I am; if you take a microscope and compare the duplicate and the original, not the slightest difference can be discovered between the two. But still more astonishing is the process called acierizing, by which a steel surface is put on the copper duplicate, the object being to prevent the wearing away of the plate under the printing operation. We hare exan ined the impressions from the acierized duplicates, and we cannot, even with the microscope, find any difference between them and the original. When we consider how extremely minute the particles or atoms of metal must be, to produce such a result, it is quite wonderful.

I think I have given you an outline of nearly all of our operations. It could only be an outline in the time allowed for a lecture of this kind; but I trust it will be sufficient to shew you that the survey has assumed a character altogether different to that from which it started, and altogether different to that which it had assumed in the south of England. Our large-scale plans have been hitherto confined to the north of England and to Scotland.. And when we hear gentleman saying that this large scale is an abominable Scotch job, I may remark that we had done a great deal more in England than in Scotland on the large scales. We have never made any distinction between the surveys of England and Scotland; it was the survey of Great Britain which was going on. We have now large parties : stationed in Cumberland and in Northumberland, and we shall have made great progress in those two counties by the end of this yenr, so that we shall shortly be able to close the gap which now exists between the surveys of England and Scotland.

With regard to the estimates for this work, we have this most surprising result from the different changes which we have made in the mode of conducting the work, and the introduction of all those mechanical appliances which I have attempted to describe. We have reduced the estimate made by my predecessor, and which is published in the correspondence upon the survey in a Parliamentary Paper, and find that the actual cost (for it is not an estimate any longer) is less than one-half the cost at which it was originally estimated. It was estimated by Colonel Hall at $2 s$. an 'acre, and we have reduced it to $11 \frac{1}{2} d$., but I will stick to 1s. to provide for contingencies. The difference of the cost, however, is such, that upon the average annual expenditure upon the survey, it is

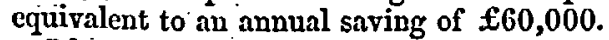

I have concluded the observations which I think it nece. ary to make with reference to the Ordnance Sturvey, but I have been requ sted by the Council of this - Society to explain the nature of the projection of the sphere which I have made, and I shall be happy to do so, because it is likely to become a very useful one, especially when we want to embrace 
Plate 3.

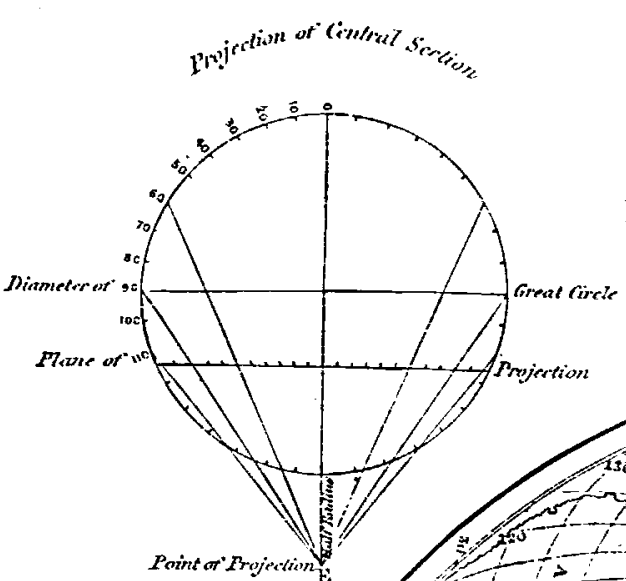

GEOMETRICAL PROJECTION

OF
TWO THIRDS OF THE SPHERE
BY

I.ieut! Colonel II.James, R.E. F.R.S. M.R.I.A.R.e.

Superintentent of the Ortumese survig:

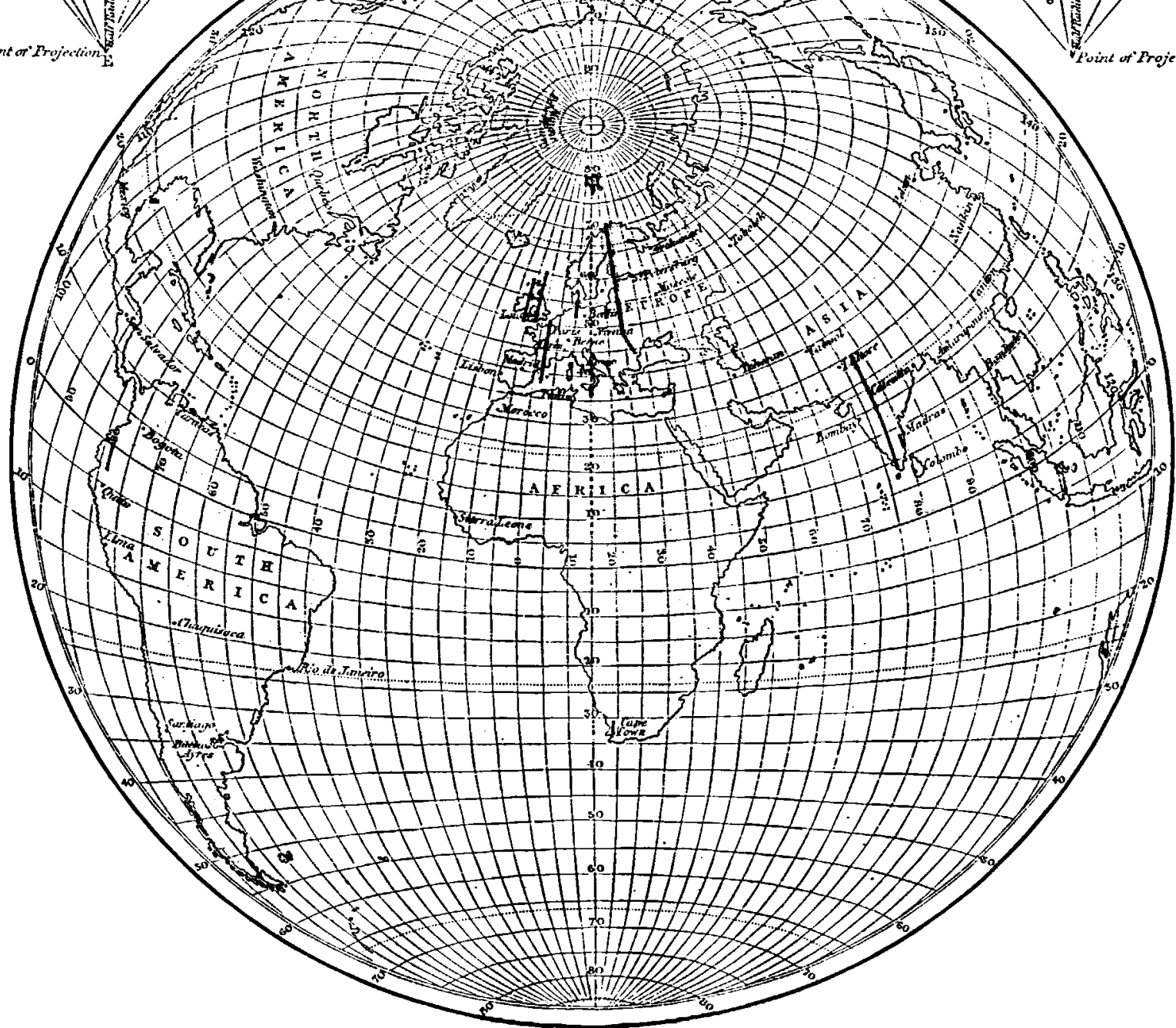

ENGRAVED aT THE ORDNANCE MAP OFFICE SOUTHAMPTON 1857

EROM A REDUCTION MADE BY PHOTOGRAPHY

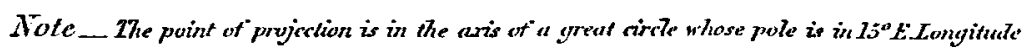
and $23^{\circ}, 30^{\prime}$ torth Lutitude and at the distance of hatf the madius above the surfure of the spluere. The plane of projection is purathel th this gretat bircte at the distunce. of $2.3^{\circ}$ 30' fram it cowards the point of projection. The projection

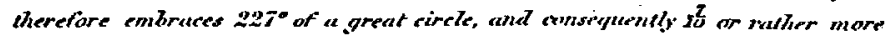

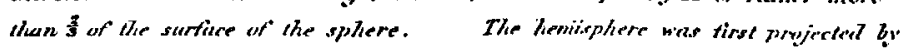

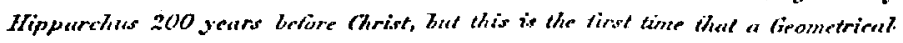
projection af more than a hernisphere has bern math.

NB. The dark lines insticule the porition of all the -neasured ares of Meridians. 
a large portion of the earth's surface at one view. The geometrical projection of the hemisphere, which is : known as the stereographic (the earliest known projection of the hemisphere) was made by Hipparchus 200 years before the birth of Christ; but it is a curious circumstance that up to the present time it seems not to have occurred to any one to make a geometrical projection of more than a hemisphere. It is remarked : by Sir John Herschel in his Outlines of Astronomy, that Falmouth is the centre of the hemisphere which embraces, the greates' amount of land and the great centre therefore of men. - In verifying thi.s fact on a globe it occurred to me to inquire what would be the centre of all the land, and I found that a point in $15^{\circ}$ east longitude and $23^{\circ} \cdot 30^{\prime}$ north latitude, was the centre of a circle embracing Europe, $\Lambda$ sia, $\Lambda$ frica, America, and a part of Australia, including two-thirds of the surface of the sphere. The question was, how that could be represented. . It seemed like an impossibility to do so, but it occurred to me that the diffictlty might be got over by imagining we were looking into the sphere and not at it. The projection is made in this manner; the eye or point of projection $E$ is at the distance of half the radius from the sphere, $\triangle B C$ is two-thirds of the sphere, and $\Lambda \mathrm{c}$ the plane of projection, on which from the point $E$ all the interior surface of $A \mathrm{~B} C$ would be seen. (Plate II. fig. 8.)

By adopting the position shown for the axis of the earth, I get the north pole or the south pole, as it may be, at the limit of the projection. Many gentlemen who have seen these projections, and Sir. Charles Lyell and others, have said that it is the first time they ever thoroughly understood the relation of one part of the earth to the other, for you cannot see it by looking at a globe or at Mercator's projection; and if you attempt to get it from the two hemispheres, your eye is thrown out, and you cannot comprehend it; but in this projection (Plate III.) you get everything round the poles, and you see the accurate relation of one part to another. Upon this projection $I$ have laid down what are called the lines of equal magnetic declination, and you will see how all those lines converge upon the magnetic pole, and upon the true pole of the earth. I have a similar projection for the southern regions and the Pacific Ocean; and we have also applied it to the projection of the stars. In this latter case it is essentially like looking into the vault of the heavens; and instead of a representation by six separate plates, as you have in Sir John Lubbock's gnomonic projection, you have two-thirds of the sphere represented at once. This projection is also particularly well suited for the representation of the isothermal and isobarometrical lines for exhibiting the direction of the winds and currents, and, as I have before said, all the great physical facts for the comprehension and exhibition of which we require to have before us the greater portion of the earth.

[Corporal Neil struck off, turing the lecture, some impressions from a zinc plate, which were exhibited, and which are now deposited in the topographical department of the Institution.]

This mode of preparing a plate for printing is exactly the reverse of the engraving process. In engraving the engraver cuts into the copper, and the ink is rubbed in previous to taking the impression; but in this process the tracing of the plan, traced with greasy ink, is laid on the zinc; the grease of the ink coming in contact with the surface of the zinc 
adheres to it; a very weak solution of gallic and phosphoric acids is then applied, which acts upon the exposed part of the plate, while the oil of the ink preserves the plate where there is any writing or drawing. The effect is that the bitten portion will not receive the ink, and the unbitten or greasy surface will, as in lithography.

You see the importance of having a simple, expeditious, and inexpensive mode of producing this 25 -inch map, by which it is brought home, so to speak, to the door of erery man, for little more than the value of the paper. We are able to strike the impressions off at the rate of 1,000 a day, and crerybody buys when they can be got so cheaply. The Government does not seek to make a profit out of them; the survey has been paid for in the taxes, and therefore it lets the people have the copies as cheaply as possible. I advocated this strongly before the Committee of the House of Commons on the survey, though a grent number. of gentlemen said "No ; make the survey and lock it up." The advantage of this process is, that it is so cheap that the sale of the maps covers the entire cost of the publication. And I will close my observations by saying that, whatever may be the case in other things, the public in this matter get thcir money's worth for their money.

Chairman.-Before we part, our thanks are due to Colonel James for his lecture. Instead of its having been a dry one, it has been very much the contrary. The subject is one which is becoming more and more important to financial as well as to military people. And I beg to tender onr very cordial thanks to Colonel James. 